Arab Univ. J. Agric. Sci., Ain Shams Univ., Cairo, 14(1), 299-316, 2006

\title{
ANTIOXIDATIVE PROPERTIES AND ANTIMICROBIAL ACTIVITY OF DIFFERENT AROMATIC EXTRACTS OF MELISSA officinalis L.
}

[20]

\author{
Helmy, Shahinaz ${ }^{1}$ A.
}

\begin{abstract}
The present study was carried out to maintain aromatic extracts of Melissa using different techniques (water distillation, steam distillation and extraction with acetone). The volatile components of these extracts were identified. Likewise, the antioxidative properties and antimicrobial activity of these extracts were determined. Data confirmed that the yield percent of acetone oleoresin extract was higher than both of water distillation and steam distillation extracts. Moreover, fractionation of volatile components using GC/MS technique showed the ability of acetone to extract more components than that of other techniques. In addition to being more effective in extracting higher amounts of sesquiterpene and phenols fractions. Odor threshold level confirmed that the concentration up to $1000 \mathrm{ppm}$ from either water distillation or steam distillation extracts could be mixed with sunflower oil without affecting its odor, while acetone oleoresin extract could be used at concentration up to $800 \mathrm{ppm}$. Likewise, the different aromatic extracts of melissa exhibited antioxidative properties on sunflower oil. However, acetone oleoresin was markedly superior to that of water distillation as well as steam distillation extracts as antioxidant agents. This could probably attributable to the high content of some active components such as phenolic compounds in the acetone oleoresin extract. Also, antioxidant synergistic effect was observed for a mixture of $200 \mathrm{ppm}$ tested extracts and BHT at $100 \mathrm{ppm}$. However, a mixture includes acetone oleoresin extract was the most effective as an antioxidant on sunflower oil. In conformity with antimicrobial activity, all tested extracts exhibited antimicrobial activities, however acetone oleoresin extract appeared the most potential antimicrobial spectra.
\end{abstract}

Keywords: Melissa, Essential oil, Oleoresin, Volatile components, Antioxidant properties, Antimicrobial activity

1- Food Sci. \& Technol. Dept., Faculty of Agric., Cairo University, Giza, Egypt

(Received September 18, 2005)

(Accepted October 4, 2005) 


\section{INTRODUCTION}

Melissa officinalis L. a native of the countries bordering on the Northern Mediterranean. It's a herbaceous plant with a strong, agreeable odor, reminiscent of lemon, so it is commonly known as lemon balm (Guenther, 1948). Moreover, the fragrance of the essential oil is green and woody (pine-like), with a floral (rosy) top note (Dawson et al 1988). It is considered one of the earliest known medicinal herb, likewise, Paracelsus called it is the "Elixir of life". It was associated particularly with nervous disorders, digestive and respiratory complaints. So it is used extensively in pharmaceutical preparations for its carminative, antihistaminic, sedative, diaphoretic and bactericidal activities (Zivanovic, et al 1990 and Lawless, 1992). It could be also used to treat Alzheimer's and Graves diseases (Akhondzadeh et al 2003). Melissa in the forms spices, essential oil as well as oleoresin is approved as generally recognized as safe (GRAS) to be used as natural seasonings and flavorings (Anon, 2003). Also, the German Standard License approved melissa tea for nervous disorders and gastrointestinal tract troubles (Wichtl and Bisset, 1994). The most producing countries are Hungary, Egypt and Italy for melissa herb while Ireland for essential oil (De Sousa, et al 2004).

In this era of increased concern on safety of chemical food additives and natural preservatives are receiving increased attention (Oiya and Muroki, 2002). Synthetic antioxidants such as butylated hydroxyl toluene (BHT) and butylated hydroxyl anisole (BHA) have been dominant in preserving fats and oils since their introduction. However, some physical properties of BHT and BHA such as their high volatility and instability at elevated temperature, strict legislation on the use of synthetic food additives and consumer preferences have shifted the attention of manufacturers from synthetic to natural antioxidants (Porter, 1980 and Polorny, 1991). Melissa has a valuable antioxidant properties (Gilsoul and Jeanfils, 1992, Moure et al 2001, De Sousa, et al 2004 and Mimica-Dukic et al 2004). Furthermore, melissa essential oil has inhibited the growth of many microorganisms (Kedzia, et al 1994 and Leao, et al 2003).

The present investigation was carried out to extract the different aromatic extracts of melissa essential oil using water as well as steam distillation or acetone extraction methods (acetone oleoresin). Besides, fractionation and identification for these extracts were performed by using GC/MS. Furthermore, assessment the antioxidant properties of these extracts was determined to prolong the shelf life of edible oils. Also, the potential of the tested extracts were examined to be used as natural inhibitor for the growth of some microorganisms.

\section{MATERIAL AND METHODS}

\section{Plant material}

The leaves and flowering tops of melissa were harvested in March, 2004 from the Medicinal Farm of Faculty of Agriculture, Cairo University, Giza, Egypt. Leaves and flowers were then dried in drying cabinet at ambient temperature $\left(28-30^{\circ} \mathrm{C}\right)$ for 2-3 days with forced ventilation.

Butylated hydroxy toluene (BHT) was purchased from Sigma Chemical Co., Poole, London, England. 
Refined sunflower oil was obtained from Arma Co. for Food Industry, $10^{\text {th }}$ of Ramadan, Egypt.

\section{Microorganisms}

Five different bacterial strains, three strains of gram positive bacteria and two strains of gram negative bacteria were used in this study. The gram positive strains were Bacillus subtilis ATCC 33221, Bacillus cereus ATCC 33018 and Staphylococcus aureus ATCC 20231. Gram- negative bacteria included Escherichia coli ATCC 6933 and Pseudomonas aeruginosa ATCC 9027. In addition to 2 strains of yeasts, Saccharomyces cerevisiae NRRLY 2034 and Candida lipolytica NRRLY 1095 and two strains of moulds include Aspergillus flavus EMCC 101and Aspergillus niger NRRL 326. All previous strains were obtained from the Egyptian Microbial Culture Collection (EMCC), Faculty of Agriculture, Ain Shams University, Cairo, Egypt with the exception of Aspergillus niger NRRL 326 which obtained from Northern Regional Research Laboratories (NRRL), Peoria, Illinois, USA. These organisms were checked for their purities and they were reactivated monthly on the suitable medium as reported by Conner and Beauchat (1984).

\section{Media}

Mueller Hinton and Sabouraud agar medium were used in the disc diffusion technique for antibacterial and antifungal assays according to Difco- Manual (1977).

\section{Methods}

\section{1- Extraction technique}

Three extraction methods were used to obtain different aromatic extracts of melissa plants as follows:

a- Water distillation method was used to get essential oil by water distillation (WD) for $6 \mathrm{hr}$ according to Guenther, 1961.

b- Steam distillation method to obtain essential oil by steam distillation (SD) for $6 \mathrm{hr}$. as described by Guenther, 1961.

c- Acetone extraction method was used to obtain acetone oleoresin (AO) by mixing one $\mathrm{Kg}$ of Melissa plant with $5 \mathrm{~L}$ freshly redistilled acetone, continuous shaking was applying for $24 \mathrm{hr}$. then the solvent was removed under reduced pressure (Dapkevicius et al 1998).

\section{Fractionation and identification of dif- ferent aromatic extracts using GC/MS}

Fifty microliter (as vapor) were analyzed by GC/MS using a Hewlett - Packard Gas Chromatography- Mass spectroscopy Model 6890 series equipped with selective Detector Mass spectroscopy Model 5973 according to the method of Guadayol et al (1997).

\section{Determination of odor threshold level}

Glass vials containing $5 \mathrm{ml}$ of sunflower oil were mixed with different concentrations of melissa aromatic extracts $(100,200,400,600,800,1000$ and 1500 ppm) and evaluated organoliptically according to ASTM (1994) . Ten panelists were demonstrated the sensory character- 
istics of oil samples by sniffing each sample and characterize its odor intensity according to the following scale: none (odor of control), 1.0 (odor different from control), 2.0 medium (very weak odor identifiable), 3.0 strong (different from control) 4.0 very strong and 5.0 extremely strong. Then the collected data were statistically analyzed using least significant differences (L.S.D) test according to the methods of Snedecor and Cochran (1980).

\section{Antioxidant activity of different aro- matic extracts}

Antioxidant stability was applied on refined sun flower by oven test method (schaal test) according to the method described by Cocks and Rede (1966). Fifty gram of fresh sunflower oil was used as control sample and another sample with 200 ppm BHT (as a synthetic anti oxidant) was used for a comparison. Also, fifty gram of sunflower oil was placed in a beaker then different concentrations from the tested aromatic extracts of melissa were added. The samples were covered with a watch glass and incubated at $63^{\circ} \mathrm{C} \pm 0.5$ till rancidity took place as detected by measuring peroxide value every two days to demonstrate the data of oven test. Furthermore, the synergistic effect of different tested extracts at 200 ppm with BHT at 100 ppm was also determined.

\section{Peroxide value}

Peroxide value was determined according to the method described in A.O.C.S. (1993).

\section{Antimicrobial activity of different ar- omatic extracts}

Disc Diffusion Assay was applied to assess the antimicrobial activity of different aromatic extracts from melissa according to the method described by Hood, et al (2003). Aromatic extracts were used in different dilutions $(0.5,1,5$, 10,20 and $50 \%$ ) using ethyl alcohol (95\%). Twenty $\mathrm{ml}$ of either Mueller Hinton agar medium (used as antibacterial activity assay) or Sabouraud agar medium (used as antifungal activity assay) contains $1 \%$ tween 80 as an emulsifier were poured in sterilized plates $(90 \mathrm{~mm}$ diameter). The Mueller Hinton agar medium was allowed to harden to $28^{\circ} \mathrm{C}$ for 30 min. A half $\mathrm{ml}$ of activated bacterial or fungal strains cultures was spread over the surface of agar plate using a sterile glass spreader. Inoculated plates were inverted and incubated at $28-32^{\circ} \mathrm{C}$ for a further $30 \mathrm{~min}$. Ten $\mu \mathrm{l}$ of each extract was placed on $6 \mathrm{~mm}$ blank antimicrobial susceptibility discs. The extracts were impregnated the discs, then they were placed onto the incubated surface of the agar plate (maximum four discs per plate). The agar plates were incubated overnight at suitable temperature $\left(30^{\circ} \mathrm{C}\right.$ for fungal strains and $37^{\circ} \mathrm{C}$ for bacterial strains). The zones of microbial inhibition were recorded.

\section{RESULTS AND DISCUSSION}

\section{The yield of aromatic extracts of melis- sa}

The percent yield of the three aromatic extracts of melissa was $0.24,0.22$ and $1.62 \%$ (v/w, dry wt. basis), respectively for $\mathrm{WD}, \mathrm{SD}$ and $\mathrm{AO}$ extracts. 
These results agree with those obtained by Adzet et al (1992) who reported that the percent of melissa essential oil obtained by steam distillation was in the average of 0.21 to $0.23 \%$ and this percent depends on many factors including leaf position, agricultural treatments and date of harvesting.

The highest percentage of AO, could be attributed to the ability of acetone solvent to extract soluble compounds such as essential oil, resins, waxes, pigments, ..... etc. which could be isolated by the solvent (Lawless, 1992).

\section{The chemical constituents of aromatic extracts of melissa by GC/MS}

Concerning fractionation and identification of volatile components, Fig. (1) shows the GC/ MS chromatogram of the melissa aromatic extracts. Although 35, 44 and 48 components were fractionated for $\mathrm{WD}, \mathrm{SD}$ and $\mathrm{AO}$, respectively, only 32, 41 and 42 components were identified. The percentages of identified components from WD, SD and AO extracts were $95.13,94.97$ and $93.88 \%$, successfully, while the maintaining portions were unknown constituents which accounted for $4.87,5.03$ and $6.12 \%$, respectively, as shown in Table (1).

The identified components were classified into 6 main groups: hydrocarbons, aldehydes \& ketones, alcohols, phenols, esters and oxides. Table (1) reveals qualitative as well as quantitative differences due to the different extraction techniques applied.

From the results presented in Table (1), it could be observed that hydrocarbons group constitutes the first predominant group for all tested aromatic extracts where it represents $34.05,33.60$ and $30.51 \%$, for $\mathrm{WD}, \mathrm{SD}$ and $\mathrm{AO}$ extracts, resp. $\beta$ - Cubebene was the most abundant compound in this group through all aromatic extracted. Such findings agreed with that obtained by Sarer and Kokdil, (1991). who revealed that the $\beta$ - cubebene comprising $15.4 \%$ from Melissa essential oil. Otherwise, Dawson et al (1988) found that $\beta$ - cubebene comprises $39 \%$ from the oil of melissa. Many hydrocarbon compounds were also found in different concentration such as $\alpha$-pinene, $\beta$ pinene, delta-carene, myrcene, $\beta$ - ocimene, $\alpha$ - copaene, limonene, phellandrene and camphene.

Concerning the difference between the extraction methods either by water or steam distillation as well as extraction with acetone, our findings showed that acetone could extract sesquiterpenes as $\beta$ caryophyllene and $\gamma$ - elemenene (as shown in Table 1) where these two compounds constitutes 3.26 and $3.50 \%$ from AO extract, resp., while they were found in lower concentrations for SD or WD extracts.

The second main group is aldehydes and ketones where it represents 22.06, 24.72 and $29.11 \%$, resp., for the three different aromatic extracts. Citronellal was the most abundant compound followed by citral This result is in the same line with that obtained by Adzet et al (1992). Moreover, the alcohol group was found to comprise 20.65, 19.98 and 15.24 $\%$, resp., for WD, SD and AO. The most abundant compounds were citronellol, linalool and geraniol. These results are in accordance with those obtained by Kedzia et al (1994). $\alpha$-Cadinol was higher in WD extract than that of SD and AO extracts. Phenol group was found to be in high concentration for AO extract $(8.74 \%)$ while it constitutes 5.8 and $6.22 \%$, resp., in WD and SD extracts. In 
Fig. 1. GC/MS chromatogram of different aromatic extracts of Melissa, (a): WD extrac, (b): SD extract, (c): AO extract 
Table 1. The chemical components of the different aromatic extracts of melissa identified by GC/MS

\begin{tabular}{|c|c|c|c|}
\hline$\overbrace{\text { Components }}^{\text {Technique }}$ & $\begin{array}{c}\text { WD extract } \\
\text { Concentration } \\
\%\end{array}$ & $\begin{array}{c}\text { SD extract } \\
\text { Concentration } \\
\%\end{array}$ & $\begin{array}{c}\mathrm{AO} \text { extract } \\
\text { Concentration } \\
\%\end{array}$ \\
\hline \multicolumn{4}{|l|}{ Hydrocarbons } \\
\hline$\overline{\alpha-\text { Pinene }}$ & 1.7 & 1.52 & 1.40 \\
\hline Carene $-\delta$ & 0.85 & 1.91 & 0.22 \\
\hline Phellandrene & 1.38 & 1.10 & 2.18 \\
\hline$\beta$-Pinene & 0.70 & 3.35 & 2.92 \\
\hline Camphene & - & 1.03 & 0.27 \\
\hline Limonene & 1.04 & 1.50 & 1.42 \\
\hline Trans- Caryophyllene & 1.05 & 2.18 & 3.01 \\
\hline Germacrene & 0.65 & 1.09 & 1.04 \\
\hline$\beta$ - Caryophyllene & 2.22 & 2.31 & 3.26 \\
\hline$\alpha$-Copaene & 2.51 & 1.01 & 0.25 \\
\hline Myrcene & 1.11 & 1.00 & 1.84 \\
\hline Ocimene $-\beta$ & 3.92 & 1.09 & 1.00 \\
\hline$\gamma$-Elemenene & - & 1.40 & 3.50 \\
\hline$\alpha$-Terpinene & - & 0.28 & 1.30 \\
\hline Cymene & - & 0.29 & - \\
\hline Bisaboline & 3.68 & 2.06 & 1.55 \\
\hline$\beta$ - Farnesene & - & 1.29 & 0.27 \\
\hline$\beta$ - Cubebene & 13.24 & 9.10 & 5.08 \\
\hline Total & 34.05 & 33.60 & 30.51 \\
\hline \multicolumn{4}{|l|}{ Alcohole } \\
\hline$\alpha$-Terpineol & 3.16 & 1.01 & 0.44 \\
\hline Citronellol & 5.22 & 10.01 & 6.86 \\
\hline Linalool & 4.42 & 1.70 & 2.10 \\
\hline$\alpha$-Cadinol & 5.70 & 2.42 & 1.70 \\
\hline Estragol & 3.30 & 2.10 & 0.22 \\
\hline Geraniol & 0.71 & 2.21 & 2.91 \\
\hline Gingerol & - & 0.22 & 0.52 \\
\hline Nerolidol & 0.24 & - & 0.27 \\
\hline Total & 20.65 & 19.98 & 15.24 \\
\hline
\end{tabular}


Continued Table, 1.

\begin{tabular}{|c|c|c|c|}
\hline $\mathrm{C}_{\text {Components }}^{\text {Technique }}$ & $\begin{array}{c}\text { WD extract } \\
\text { Concentration } \\
\%\end{array}$ & $\begin{array}{c}\text { SD extract } \\
\text { Concentration } \\
\%\end{array}$ & $\begin{array}{c}\text { AO extract } \\
\text { Concentration } \\
\%\end{array}$ \\
\hline \multicolumn{4}{|l|}{ Aldehydes \& Ketones } \\
\hline 2- Propanone & 0.71 & 0.29 & 0.74 \\
\hline Acetone & - & - & 1.31 \\
\hline Hexanone & 0.30 & - & 0.97 \\
\hline Carvone & - & 1.70 & 2.10 \\
\hline Butanone & - & - & 2.01 \\
\hline Citral & 5.82 & 7.90 & 8.92 \\
\hline Hexanal & - & 0.70 & 0.72 \\
\hline Citronellal & 11.42 & 12.06 & 12.01 \\
\hline Geranial & 3.81 & 2.07 & 0.33 \\
\hline Total & 22.06 & 24.72 & 29.11 \\
\hline \multicolumn{4}{|l|}{ Phenols } \\
\hline Anethole & 3.20 & 0.83 & 0.72 \\
\hline Eugenol & 2.05 & 4.01 & 6.01 \\
\hline Methyl eugenol & - & 0.24 & 0.21 \\
\hline Carvacrol & 0.33 & 0.42 & 0.50 \\
\hline Thymol & 0.22 & 0.32 & 1.30 \\
\hline Total & 5.80 & 6.22 & 8.74 \\
\hline \multicolumn{4}{|l|}{ Esters } \\
\hline$\overline{\text { Linalyl }}$ acetate & 1.19 & 2.02 & 0.27 \\
\hline Borenyl acetate & - & 1.40 & - \\
\hline Geranyl acetate & 0.21 & 1.00 & 1.00 \\
\hline Total & 1.40 & 4.42 & 1.27 \\
\hline \multicolumn{4}{|l|}{ Oxides } \\
\hline Caryophyllene oxide & 6.20 & 1.02 & - \\
\hline 1,8 Cineole & - & 0.31 & 0.11 \\
\hline Total & 6.20 & 1.33 & 0.11 \\
\hline $\begin{array}{l}\text { Total identified } \\
\text { compounds }(\%)\end{array}$ & 95.13 & 94.99 & 93.88 \\
\hline $\begin{array}{l}\text { Total unidentified } \\
\text { compounds }(\%)\end{array}$ & 4.87 & 5.01 & 6.12 \\
\hline
\end{tabular}


this concept, eugenol was the most abundant compound.

Regarding ester group compounds, the total amount of this group recorded the highest percentage for SD extract (4.42\%). Meanwhile, WD and AO 1.4\% and $1.27 \%$, resp. of ester group. Linalyl acetate and geranyl acetate were found in all tested extracts while borenyl acetate was found only in SD extract. The oxides group was included caryophyllene oxide where it was found in WD and SD extracts only.

According to the investigation applied by Orth et al (1993), they revealed that caryophyllene oxide indicates an essential oil of minor quality where it could be presented by oxidation of the aliphatic double bond of caryophyllene (it increased from 0 to $17 \%$ during storage at room temperature for 10 months). This compound was found also in essential oil extracted with hydrodistillation technique from German melissa as reported by Adzet et al (1992). Our findings upheld this result especially, in the view of a decrement in citral content in either WD or SD extracts which purported that citral is converted to caryophyllene oxide in these two extracts.

From the above mentioned and discussed results, it could be concluded that AO extract seems to be a selective and particular efficient for isolation of sesquiterpene and phenol fractions, likewise avoiding oxidation which could produce undesirable compound such as caryophyllene oxide.

Odor threshold levels of sunflower oil mixed with different aromatic extracts of melissa

The odor threshold levels was determined to identify the acceptability of sun- flower oil mixed with the tested extracts. Data presented in Table (2) indicates that both WD and SD extracts were preferable at concentrations 100 up to $1000 \mathrm{ppm}$. Meanwhile AO extracts was not preferably at concentrations exceed $800 \mathrm{ppm}$, so different concentrations of tested extracts had been chosen after adding to sunflower oil for studying the antioxidative properties of these extracts. Tested extracts were graduated ascendingly from 200 ppm up to $1000 \mathrm{ppm}$ for WD and SD extracts, while that level was up to 800 ppm for AO.

\section{Antioxidative properties of melissa aromatic extracts on sunflower oil}

The oxidative stabilities of sunflower oil with or without synthetic (BHT) or natural antioxidant (the three aromatic extracts of melissa) were studied, the obtained results are shown in Table (3). It could be observed that addition of BHT as a synthetic antioxidant prolonged induction period up to $325 \mathrm{hr}$ which increased relative stability by $116.91 \%$ compared with the control oil (without any additives antioxidant) which recorded $278 \mathrm{hr}$ as induction period. Meanwhile addition of different aromatic extracts of melissa (even at lower concentrations as 200 ppm) caused slight increment in relative stability of sunflower compared to control oil. These antioxidant properties being increased with increasing the concentration of aromatic extracts where the relative stability of sunflower oil at 1000 ppm for WD and SD was 118.35 and $119.78 \%$, resp., compared to $116.91 \%$ for sunflower oil with 200 ppm BHT. Likewise, AO extract exhibited the highest antioxidative properties especially, at concentrations of 400 and $800 \mathrm{ppm}$ that 
Table 3. Antioxidant activity of different aromatic extracts of melissa on the induction period of sunflower oil compared with BHT

\begin{tabular}{|c|c|c|}
\hline Samples & $\begin{array}{l}\text { Induction period* } \\
(\mathrm{hr})\end{array}$ & $\begin{array}{c}\text { Relative stability } \\
(\%)\end{array}$ \\
\hline Sunflower oil (control) & 278 & 100.00 \\
\hline \multicolumn{3}{|l|}{ Melissa extracts } \\
\hline \multicolumn{3}{|l|}{ WD extract: } \\
\hline 200 & 292 & 105.04 \\
\hline 400 & 309 & 111.15 \\
\hline 1000 & 329 & 118.35 \\
\hline \multicolumn{3}{|l|}{ SD extract: } \\
\hline 200 & 303 & 108.99 \\
\hline 400 & 316 & 113.67 \\
\hline 1000 & 333 & 119.78 \\
\hline \multicolumn{3}{|l|}{ AO extract: } \\
\hline 200 & 313 & 112.59 \\
\hline 400 & 321 & 115.47 \\
\hline 800 & 343 & 123.38 \\
\hline \multicolumn{3}{|c|}{ Synergistic effect of BHT and melissa extracts } \\
\hline WD extract (200 ppm) + BHT(100 ppm) & 322 & 115.83 \\
\hline SD extract $(200 \mathrm{ppm})+\mathrm{BHT}(100 \mathrm{ppm})$ & 326 & 117.27 \\
\hline $\mathrm{AO}$ extract $(200 \mathrm{ppm})+\mathrm{BHT}(100 \mathrm{ppm})$ & 330 & 118.70 \\
\hline
\end{tabular}

* Induction period was determined using oven test at $63 \pm 0.5^{\circ} \mathrm{C}$.

Induction period refers to the time (hr) at the break point of the two extra polated straight parts of the curve.

was superior to that of either WD or SD extracts at the same concentrations, where the relative stabilities were 115.47 and $123.38 \%$, resp. These results are in agreement with those obtained by Mimica-Dukic et al (2004) who showed that melissa essential oil recorded high induction in lipid peroxidation. Regarding, the elucidation of antoxidant activity of melissa aromatic extracts, Hohmann et al (1999) pointed out that the phenolic compounds were responsible for antioxi- dant activity. Also Andarwulan et al (1999) showed that there is a positive relationship between phenolic content and antioxidant activity. In this concern, El-Ghorab et al (2004) demonstrated the higher antioxidative properties of marjoram essential oil extracted by supercritical $\mathrm{CO}_{2}$ than that extracted by water distillation, they ascertained that the higher antioxidant activity is due to the increment in phenolic constituents. 
Another interpretation was reported by Tagashira and Ohtake, (1998) who found that both rosmarinic acid and 1, 3 benzodioxole compounds shown to possess antioxidative activity, however rasmarinic acid is the most effective. They also added that these two compounds showed a ten-fold greater antioxidant activity than either vitamin $\mathrm{C}$ or vitamin E.

Furthermore some hydrocarbons like $\alpha$-terpinene exhibited antioxidant activity (El-Ghorab et al 2004). This compound was found in AO and SD extracts at concentration 1.30 and $0.28 \%$ resp., while it wasn't found in WD extract (as shown in Table 1). Another hydrocarbons exhibited adoptive antioxidant activity are $\beta$ myrcene, limonene as monoterpenes and trans-caryophellene as sesqueterpene (Badee, et al 2005).

The previous compounds were found in the different aromatic extracts of melissa as illustrated in Table 1. Moreover, AO extract contains higher concentration of these compounds followed by SD extract.

In general, the antioxidant activity of different aromatic extracts of melissa may be due to the existence of some volatile compounds such as thymol and carvacrol (phenols) as well as gingerol (alcohols) as reported by Aeschbach, et al (1994), esp., these previous components were found in AO with considerably high concentrations compared with those found in SD and WD, resp., (as shown in Table $1)$.

With regard to the difference between the extraction methods that used in this investigation, solvent extraction was more effective. This also upheld by Julkunen- Tiito, (1985) and Marinova and Yanishieva (1997) who showed that the yield as well as antioxidant properties dependent on type of solvent.

In order to enhance the antioxidant activity of the natural extracts examined and decreased the applicability of synthetic antioxidants, the synergistic effect was determined by adding $100 \mathrm{ppm}$ BHT to $200 \mathrm{ppm}$ of different melissa extracts. Results presented in Table 3 showed that the mixture of BHT with either extract exhibited an additional effect of their antioxidant properties in comparison to its individual activities.

\section{Antimicrobial activity of different ar- omatic extracts of melissa}

The antimicrobial activity of three different extracts of melissa at different concentrations are presented in Table (4). It could be noticed from the results that, using dilutions $0.5 \%$ as well as $1 \%$ of the extracts did not inhibit any growth of bacteria with the exception of $1 \%$ concentration of $\mathrm{AO}$ which inhibited the growth of Escherichia coli ATCC 69337 and Staphylococcus aureus ATCC 20231. Regarding the effect of different aromatic extracts on the growth of Bacillus subtilis, results in Table (4) revealed that SD extract exhibited higher antibacterial activity compared with that of WD extract, meanwhile AO showed more effective against this strain especially at 20 and $50 \%$ where the inhibition zone was 25 and $90 \mathrm{~mm}$, respectively.

Obviously, no antibacterial activity was recorded against Bacillus cereus ATCC 33018 at concentration less than $10 \%$ of the tested aromatic extracts, while the antibacterial spectrum was found at $10 \%$ of all tested extracts with higher inhibition zones possess AO, while the effect of WD was almost the same to 
Arab Univ. J. Agric. Sci., 14(1), 2006 
that of SD extract. Also, it could be noticed that the antibacterial activity of the different extracts of melissa were directly proportion to the concentration of the tested extracts.

Concerning, effect of different aromatic extracts on the growth of Staphylococcus aureus, data revealed that both $\mathrm{AO}$ and SD extracts showed higher activity against its growth compared to that of WD extract.

Regarding the effect of aromatic extracts on the growth of Pseudomonas aeruginosa, $10 \%$ concentration of $\mathrm{AO}$ was more effective in diminishing the growth where the inhibition zone was 17 $\mathrm{mm}$ by AO. Also it could be observed that antibacterial activity of the tested extracts was positively correlated with their concentrations.

Concerning the antifungal activity of the different aromatic extracts of melissa, it could be observed that at $10 \%$ of $\mathrm{AO}$ or $20 \%$ of WD or SD inhibition zone was similar against Candida albicans NRRLY 1095 while at $50 \%$ of AO or SD extracts, no growth of fungi could be detected. In this concept, Saccharomyces cerevisiae NRRLY 2043 was more resistance to all the examined extracts where at $20 \%$ aromatic extracts, the inhibition zones were 10,10 and $12 \mathrm{~mm}$, resp., for WD, SD and AO extracts.

Regarding the two strains of molds, results reflected that Aspergillus niger was more sensitive than Aspergillus fla$v u s$, especially, to $\mathrm{AO}$ and $\mathrm{SD}$ extracts at $10 \%$ where both of the two extracts were inhibited the growth of fungi with high efficiency, where the inhibition zones were 21 and $19 \mathrm{~mm}$, resp. Nevertheless, the inhibition zone was only $15 \mathrm{~mm}$ by using 10\% WD extract. Also Antifungal activity of different melissa extracts was found to suppress the growth of Aspergillus flavus.

Concerning the antimicrobial activity of melissa, Kedzia et al 1994 and Mimica-Dukic et al (2004) reported that essential oil of melissa inhibited the growth of Staphylococcus aureus, Streptococcus faecalis and Candida albicans with MIC(minimum inhibitory concentration) values of 100, 250 and $300 \mathrm{mg} / \mathrm{ml}$ while Escherichia coli and Pseudomonas aeruginosa inhibited by $500 \mathrm{mg} / \mathrm{ml}$ media. They also added that citronellol, betacaryophyllene, thymol, carvacrol and citronellal were the most active essential oil component against microorganisms. Another studies reported that eugenol was the most effective against Staphylococcus aureus. Another investigations showed that eugenol and thymol were capable of inhibiting the growth of Escherichia coli and Bacillus subtilis (Rhayour, et al 2003). Likewise, Kim, et al (1995) demonstrated that carvacrol had a potent bactericidal activity against many foodborne pathogens including $E$. coli.

Also citral (aldehyde compound) also exhibited antibacterial activity against Staphylococcus aureus (Deans, et al 1992). In addition to the antibacterial of thymol against Staphylococcus aureus and Salmonella typhimurium (Juven, et al 1994). Regarding, the antifungal activity, Leao, et al (2003) showed that melissa essential oil was the most active oil against food spoilage yeasts and the fungitoxic effect may be due to citral and geranial

Regarding the interpretation of the antimicrobial activity of essential oil, Eklund, (1985) and Davidson et al (1993), showed that the mode of action was due to phenolic compounds which thought to involve interference with func- 
tions of cytoplasmic membrane including proton motive force and active transport.

Otherwise, Juven et al (1994) hypothesized that inhibition by thymol of Salmonella typhimurium was due to a reaction with proteins in the cytoplasmic membrane of microorganism that caused changes in membrane permeability. In another explanation, the antimicrobial activity might be due to provoke damage as holes in the envelop (in the cell wall) which observed in E. coli and Bacillus subtilis by scanning with electronic microscope. These changes were due to the phenolic compounds (thymol and eugenol) which presented in organo and clove essential oils as reported by Rhayour, et al (2003). From the previous results, it could be concluded that the higher antimicrobial activity of $\mathrm{AO}$ may be due to the existence of some active components, which extracted with acetone such as citronellol, beta-caryophyllene, thymol, carvacrol, citronellal, thymol, eugenol (Table 1) which represented in high concentrations in this extract followed by SD extract.

Summarily, different aromatic extracts of melissa exhibited antimicrobial activity. The antimicrobial activity of these extracts could be arranged in the following descending order: $\mathrm{AO}>\mathrm{SD}>$ WD.

Finally, it is interested to note that melissa aromatic extracts could be used in food products as a flavorings, antioxidant and antimicrobial agents.

\section{REFERENCES}

Aeschbach, R.; J. Xoliger; B.C. Scott; J. Butler; B. Halliwell and O.I. Aruoma (1994). Antioxidant actions of thymol, carvacrol, 6-gingerol, zingerone and hydroxytyrosol. Food Chem. Toxicol., 32: 31-36.

Adzet, T.; R. Ponz; E. Wolf and E. Schulter (1992). Content and composition of $M$. officinalis oil in relation to leaf position and harvest time. Planta Med., 58:262-264.

Akhondzadeh, S.; M. Norooziam; M. Mohammad, S. Ohadinia; A.R. Jamshidr and M. Khani (2003). Melissa officinalis in the treatment of patients with mild to moderate Alzheimer's diseases. J. Neurology Neurosurgery and Psychiatry, 74(7): 863-866.

Andrawulan, N.; D. Fardiaz; G.A. Wattimena and K. Shelty (1999). Antioxidant activity associated with lipid and phenolic mobilization during seed germination of Pangium edule Reinw. J. Agric.

Food Chem., 47: 3158-3163.

Anon (2003). Substances Generally Recognized as Safe (GRAS). Code of Federal Regulations Title 21 Food and Drugs. Spices and other Natural Seasonings and Flavorings. (182.10, 61FR 14246, April, 1996). Essential Oils, Oleoresins (solvent-free) and Natural Extractives (including distillates). (182.20, 50 FR 21043 and 21044, May 22, 1985). A.O.C.S. (1993). Officinal Methods and Recommended Practices of the American Oil Chemists Soc., $4^{\text {th }} \boldsymbol{E d}$. Pub. by the American Oil Chem. Soc., 1608 Broadmoo, Drive, Champaign, Illionis 618263489, USA.

ASTM (1994). American Society for Testing and Materials: Standard Practice for Sensory Evaluation of Edible Oils and Fats. E 1627, Reapproved 1997. Badee, A.Z.M.; M.A. El-Nikeety and M. I. Abd El-Hady, (2005). Antioxidant activities of carrot herb, mandarin peel, Clementine peel and petitgrain mandarin 


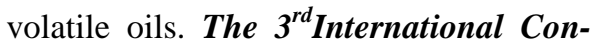
ference of Food Sci. \& Technol., 99-104. Cocks, L.V. and C.V. Rede (1966). Laboratory Handbook for Oil and Fat Analysis. pp. 340 - 341. Academic press, New York.

Conner, D. E. and L. R. Beauchat (1984). Effect of essential oils from plants on growth of food spoilage yeasts. J. Food Sci., 49: 429-432.

Dapkevicius, A.; R. Venskutonis; T.A. Van Beek and J.P. Linssen (1998). Antioxidant activity of extracts obtained by different isolation procedures from some aromatic herbs grown in Lithuania. J. Sci. Food Agric., 77: 140-146.

Davidson, P.M.; S.L. Post and A.L. Branneen (1993). Naturally Occurring and Miscellaneous Food Antimicrobials. pp. 371-419. Marcel Dekker Inc., New York.

Dawson, B.S.W.; R.A. Franich and R. Meder (1988). Essential oil of Melissa officinalis L. subsp. allissima (sibthr. El Smith) Arcang. Flavor and Fragrance J. 3(4): 167-170.

Deans, S.G.; K.P. Svoboda; M. Gundidza and E.Y. Brechany (1992). Essential oils profiles of several temperate and tropical aromatic plants: their antimicrobial and antioxidant activities. Acta Hortic., 306: 229-232.

De Sousa, A.C.; C.S. Alvia; A.F. Blank; P.B. Alves, and L. Gattass (2004). Melissa officinalis L. essential oil: antitumoral and antioxidant activities. $\boldsymbol{J}$. Pharm. and Pharmacol., 56(5):677.

Difco - Manual (1977). Dehydrated Culture Media and Reagent Microbiological and Clinical Laboratory Procedures. $9^{\text {th }}$ Ed. pp.582-585. Pub. Difco Lab., Detroit, Michigan, USA.

Eklund, T. (1985). Inhibition of microbial growth at different $\mathrm{pH}$ levels by ben- zoic and propoionic acids and esters of $\mathrm{p}$ hydroxybenzoic acid. Int. J. Food Microbiol., 2:159-164.

El-Ghorab, A.H.; A.F. Mansour and K.F. El-Massry (2004). The effect of extraction methods on the chemical composition and antioxidant activity of Egyptian marjoram (Marjorana hortensis Moench). Flavor and Fragrance $J$. 19:54-61.

Gilsoul, J.J. and J. Jeanfils (1992). Antioxidative activity of Picea abies and Melissa officinalis extracts on peanut oil. Bulletin de la Societe Botanique de France, Lettres Botaniques, 139(1): 3543.

Guadayol, J.M.; T. Baquero and J. Caixach (1997). Application of head space techniques to extraction of volatile organic compounds from paprika oleoresin. Grasas Y Aceites, 48(1):1-5.

Guenther, E.S. (1948). The Essential Oil. Vol. III, pp. 395-399. Van Nostrand Co., Inc., New York.

Guenther, E.S. (1961). The Essential Oils. Vol. I and IV, $4^{\text {th }}$ Ed.pp.95-97. Van Nostrand Co., Inc., New York.

Hohmann, J.; I. Zupko; D. Redei; M. Csany; G. Falkay; I. Mathe and G. Janicsak (1999). Protective effects of the aerial parts of salvia officinalis, Melissa officinlis and Lavandula angustifolia and their constituents against enzymedependent and enzyme-independent lipid peroxidation. Planta Medica, 65(6):576578.

Hood, J.R.; J.M. Wilkinson and H.M.A. Cavangh (2003). Evaluation of common antibacterial screening methods utilized in essential oil research. $\boldsymbol{J}$. Ess. Oil. Res., 15:428-433.

Julkunen - Tiito, R. (1985). Phenolic constituents in the leaves of northern willows. Methods for the Analysis of certain 
phenolics. J. Agric. Food Chem., 33: 231-217.

Juven, B.l.; J. Kanner; F. Schved and H. Weisslowicz (1994). Factors that interact with the antibacterial action of thyme essential oil and its active constituents. J. Appl. Bact., 76: 626-631.

Kedzia, B.; M. Krzyzaniak; K.E. Holderna; H.E. Kedzia and E. Segiet Kujawa, E. (1994). Composition and antimicrobial characteristics of melissa and its components. Herba-Polonica, 40 (1-2): 5-11.

Kim, J.M.; M.R. Marshall and C.I. Wei (1995). Antibacterial activity of carvacrol, citral and geraniol against Salmonella typhimurium in culture medium on fish cubes. J. Food Sci., 60(6): 1364 1374.

Lawless, J. (1992). The Encyclopedia of Essential Oils. The complete guide to the use of aromatics in aromatherapy herbalism. pp. 47-48. Health \& Well-being. Leao, C.; M. Ferreira and M.J. Sousa (2003). Activity of essential oils from Mediterranean Lamiaceae species against food spoilage yeasts. J. Food Prot.: 66(4): 625-632.

Marinova, E.M. and N.V. Yanishieva, (1997). Antioxidative activity of extracts from selected from selected species of the family Lamiaceae in sunflower oil. Food Chem., 58: 245-248.

Mimica - Dukic, N.; B. Bozin; M. Sokovic and N. Simin (2004). Antimicrobial and antioxidant activities of Melissa officinalis L. (Lamiaceae) essential oil. J. Agric. Food. Chem., 52(9): 2485- 2489.

Moure, A.; J.M. Cruz; D. Franco; J. M. Dominguez; J. Sineiro; $H$. Dominguez; M.J. Nunez and J.C. Para- jo (2001). Natural antioxidants from residual sources. Food Chem., 72:145-171. Oiya, S.O. and N.M. Muroki (2002). Use of spices in foods. The J. of Food Technol. in Africa, 7: 39-44

Orth, M.; T. VandenBerg and F.C. Czygan (1993). Aldehyde - dependent caryophyllene oxide formation in essential oils during storage. Planta Medica, 59: 633-634.

Polorny, J. (1991). Natural antioxidants for food use. Trends Food Sci. Technol., Sept., 223-227.

Porter, W.L. (1980). Recent Trends in Food Application of Antioxidants. C.F. Dapkevicius, et al (1998).

Rhayour, K.; T. Bouchikhi; A. Tantaovi-Elaraki; K. Sendide and A. Remmal (2003). The mechanism of bactericidal action of organo and clove essential oils and their phenolic major components on Escherichia coli and Bacillus subtilis. J. Ess. Oil Res., 15: 356-362.

Sarer, E. and G. Kokdil (1991). Constituents of the essential oil from Melissa officinals. Planta Medica, 57(1): 89-90.

Snedecor, G.W. and W.C. Cochran (1980). Statistical Methods. $7^{\text {th }}$ Ed. The Iowa State Univ. Press, Ames, Iowa, USA.

Tagashira, M. and Y. Ohtake (1998). A new oxidative 1,3- benzodioxole from Melissa officinalis. Planta Medica, 64: 555-558.

Wichtl, M. and N.G. Bisset (1994). Herbal Drugs and Phytopharmaceuticals. p. 205. Medpharm Scientific Publishers, Stuttgart, Germany.

Zivanovic, L.J.; M. Jovanovic; M. Mutavdzic; Z. Djuric and S. Agatonovic (1990). Densitometric determination of monoterpenoids in melissa extracts. Fitoterapia, 61(1): 82-83. 


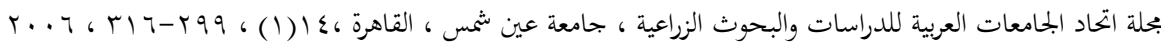

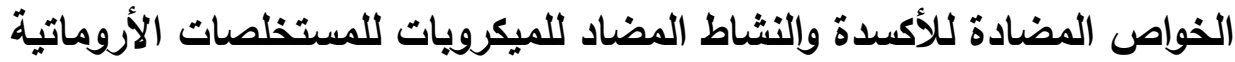 المختلفة من نبات الميليسا
}

$[r \cdot]$

\author{
شاهيناز أحمد حلمي' \\ 1 - قسم الصناعات الغذائية - كلية الزراعة - جامعة القاهرة - الجيزة - مصر
}

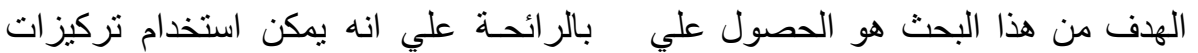

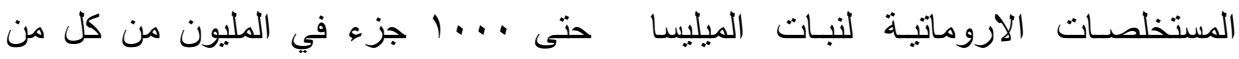

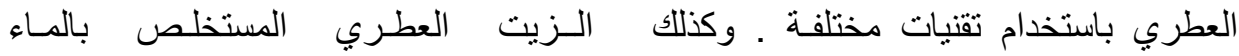

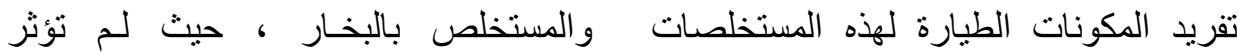

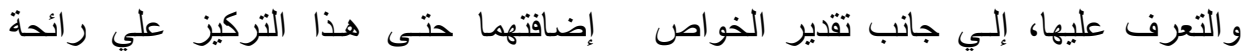

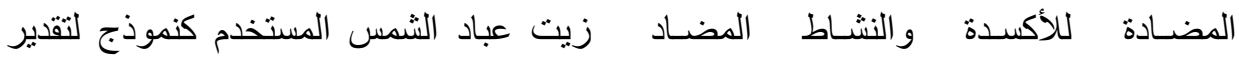

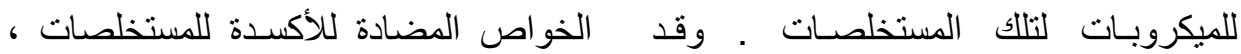

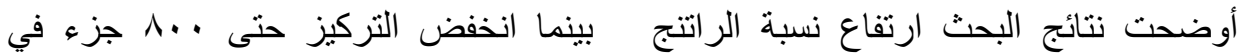

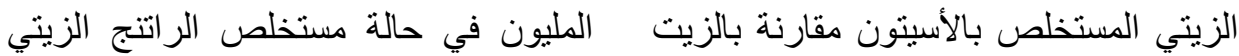

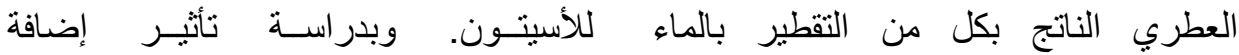

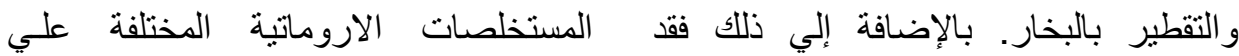

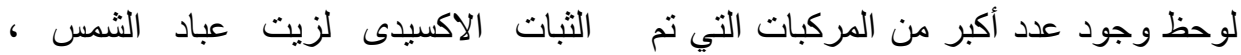

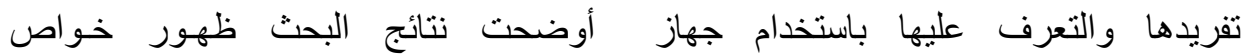

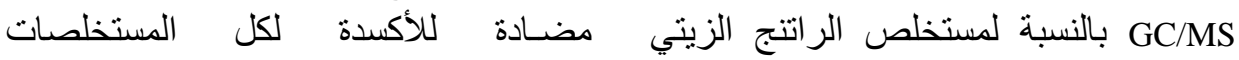

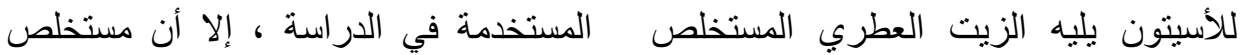

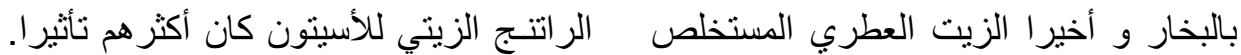

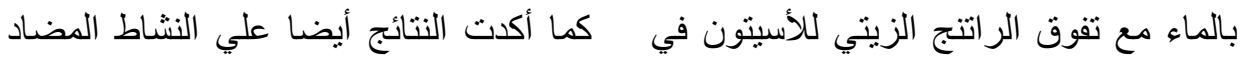

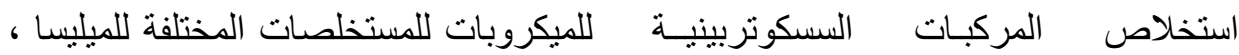

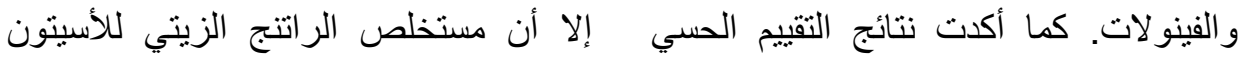
المستخدم لتحديد أقل مستوى يعطي إحساسا كان أكثر فاعلية في هذا الصدد. تحكيم: أ.د نجوى موسى حسن رسمى أ.د منى محمد عبد المجيد نصر 